Bulgarian Academy of Sciences. Space Research and Technology Institute.

Aerospace Research in Bulgaria. 30, 2018, Sofia

DOI: https://doi.org/10.3897/arb.v30.e01

\title{
EXAMINATION OF THE RELATIONSHIP BETWEEN SOLAR ACTIVITY AND EARTH SEISMICITY DURING THE WEAK SOLAR CYCLE 23
}

\author{
Mohamed Semeida ${ }^{I}$, Sara Khodairy ${ }^{1}$, Mahmoud El Hadidy ${ }^{1}$ \\ Rabab Abdel Hamed ${ }^{1}$, Shahinaz Youssef', \\ Penka Stoeva ${ }^{3}$, Alexey Stoev ${ }^{3}$ \\ ${ }^{I}$ National Research Institute of Astronomy and Geophysics, Helwan, Egypt \\ ${ }^{2}$ Astronomy, Space Science and Meteorology Department, Cairo University, Cairo, Egypt \\ ${ }^{3}$ Space Research and Technology Institute - Bulgarian Academy of Sciences \\ e-mail:m_semeida@yahoo.com; penm@abv.bg
}

\begin{abstract}
The relations between sunspot number, sunspot areas, solar $10.7 \mathrm{~cm}$ radio flux, solar proton events and earthquakes of magnitude $M \geq 5$ and $M \geq 8$ during the time interval between 1996 and 2008 of the solar cycle 23 have been analyzed in this work. We have found that there is a direct relation between solar activity and Earth seismic activity for $M \geq 5$ and $M \geq 8$, near the maximum of the Solar cycle 23 , and an inverse relation between them at the descending phase of the cycle.
\end{abstract}

\section{Introduction}

Most of the studies about the relation between solar activity and earthquakes have a cyclicity of about 11 and 22 years like the solar activity cycles. The solar cycle 23 seems to be of a great interest for the researchers due to many peculiarities. Some scientists believe that solar activity can cause earthquakes, volcanoes or extreme weather, and solar activity, presented by sunspots, radio noise and geomagnetic indices, plays a significant but by no means exclusive role in the triggering of earthquakes.

It is well known that various kinds of solar transient activities such as solar flares, disappearing filaments and coronal mass ejections (CMEs) are responsible for strong interplanetary disturbances and corresponding geomagnetic disturbances. Terrestrial effect of these activities as abrupt accelerations in the Earth's angular velocity or surges of telluric currents in the Earth's crust are the actual coupling mechanisms which trigger quakes. Scientists also found that, earthquakes occur frequently around the years of minimum solar activity. Generally, the earthquake activities are relatively less during the peak of the solar activity cycle, some say, around the period of polarity reversal. And also, the earthquake frequency in the period of solar activity minimum is closely related to the maximum annual means of sunspot numbers, the maximum annual means of solar $10.7 \mathrm{~cm}$ radio flux and solar 
proton events of the whole solar cycle. The relation between earthquakes and solar proton events is closer than the others [1].

Most of earthquakes are induced by the mutual squeeze and collision of the earth crustal plates. However, many geophysicists do not deny that any disaster cannot be attributed to the Earth's own motion. The Sun is the energy source of the Earth. Amendments of its activity influence and modulate the motion and change the whole Earth or its certain part. Therefore, many studies about the relation between solar activity and earthquake activity have come out. Generally, most of these studies investigate the relation between the recurrent variation of sunspot number and earthquake activity. Sytinskiy $[2,3]$ carried out a series of research on the influence of solar activity on the earth's seismicity. Simpson [4] found that maximum quake frequency occurs at times of moderately high and fluctuating solar activity. Lursmanashvili [5] carried out series of research on the influence of solar activity on the Earth's seismicity and speak about a possibility of influence of the Sun activity on earthquake distribution in the Caucasus. The team led by Zhang, G. Q. and Odintsov $[1,6]$ studied the long period tendency in global earthquake geomagnetic activity and some simple relationships between solar activity and global number of earthquakes with magnitude equal and larger than $4(\mathrm{M} \geq 4)$. The authors Zhang, G. Q., Dorman, L. I. and Gerontidou [1, 7, 8] found that internal effects such as subsidence, volcanic and tectonic effects are not the only reason of earthquake but also earthquakes can be triggered by some external effects such as cosmic rays, magnetic field and solar activity. The team led by Courtillot, V. [9] explained that the radiations emitted from the Sun not only have very serious effects on the Earth's atmosphere, but also affect the Earth's surface. Low level clouds, ocean temperatures, land temperatures, tropospheric temperatures, and earthquakes are shown as evidences. Khain, V. E. and Khalilov, E. N. [10] found that the periodicity of solar activity have an influence upon the periodicity of geodynamic processes. Marilia, T. and Anibal, A. [11] inspected possible influence of solar cycles on earthquakes using statistical analyses. Their results show that a significant increase in earthquake events in some of the tectonic plates is linked to solar maxima. The team led by Nikouravan, B. [12] studied in details the relationship between sunspot number, solar $10.7 \mathrm{~cm}$ radio flux, solar irradiance, solar proton events and earthquake events in Iran.

\section{Data used}

The studied solar cycle is 23 rd solar cycle since 1755 , when extensive recording of sunspot activity began. The solar cycle lasted 12.6 years, began in May 1996 and ended in January 2008. The maximum smoothed sunspot number (monthly number of sunspots averaged over a twelve-month period) observed during the solar cycle was 120.8 (March 2000), and the minimum was 1.7. There were a total of 805 days without sunspots during this cycle [13]. Sunspot number (annual mean or yearly average) are taken from SIDC web site (Solar Influence Data Analysis 
Center), data for solar proton events (>100 MEV) are taken from NOAA/NGDC (National Geophysical Data Center) web site, sunspot area data from Royal Observatory, Greenwich USAF/NOAA Sunspot Data site, and 10.7 solar radio flux (yearly average observed flux) data were taken from Space Weather Canada (Natural Resources Canada) web site for the 1996-2008 time period. Earthquake activity data had been collected from National Earthquake Information Center - NEIC / U.S. Geological Survey - USGS, with magnitude $M \geq 5$ for the same time period. This solar cycle has 7141 total number of earthquakes, 6059 earthquakes with $\mathrm{M} \geq 5$, 930 earthquakes with $M \geq 6,140$ earthquakes with $M \geq 7$ and 12 earthquakes with $\mathrm{M} \geq 8$.

Large earthquakes, with $\mathrm{M}=8.1$ took place in 1998,1 with $\mathrm{M}=8$ took place in 2000,1 with $\mathrm{M}=8.4$ took place in 2001 , 1 with $\mathrm{M}=8.3$ took place in 2003,2 with $\mathrm{M}=8.1,9.1$ took place in 2004,2 with $\mathrm{M}=8,8.3$ took place in 2006 and 4 with $\mathrm{M}=8.1,8.1,8$, and 8.5 took place in 2007, as shown in Table 1. Here we divide the data into two categories according to the magnitude of earthquakes $(M \geq 5$ and $\mathrm{M} \geq 8$ ) and compare them with the corresponding solar data. It has been carried out some statistical analysis showing the relation between the solar activity and the corresponding earthquake activity.

Table 1 illustrates the 12 large earthquakes occurred during solar cycle 23 (from May 1996 to January 2008) and show their time, depth, magnitude, latitude and longitude.

Table 1. Large earthquakes during solar cycle 23

\begin{tabular}{|c|c|c|c|c|c|c|c|c|c|}
\hline No. & Year & Month & Day & Hour & Min. & Depth & Magnitude & Latitude & Longitude \\
\hline 1 & 1998 & 3 & 25 & 3 & 12 & 20.1 & 8.1 & -63.90 & 149.61 \\
\hline 2 & 2000 & 11 & 16 & 4 & 54 & 27.6 & 8 & -3.99 & 153.26 \\
\hline 3 & 2001 & 6 & 23 & 20 & 33 & 32 & 8.4 & -16.38 & -73.50 \\
\hline 4 & 2003 & 9 & 25 & 19 & 50 & 27 & 8.3 & 41.86 & 143.87 \\
\hline 5 & 2004 & 12 & 23 & 14 & 59 & 3.5 & 8.1 & -49.33 & 161.42 \\
\hline 6 & 2004 & 12 & 26 & 0 & 58 & 30 & 9.1 & 3.30 & 95.98 \\
\hline 7 & 2006 & 5 & 3 & 15 & 26 & 55 & 8 & -20.15 & -174.10 \\
\hline 8 & 2006 & 11 & 15 & 11 & 14 & 10 & 8.3 & 46.58 & 153.27 \\
\hline 9 & 2007 & 1 & 13 & 4 & 23 & 10 & 8.1 & 46.23 & 154.55 \\
\hline 10 & 2007 & 4 & 1 & 20 & 39 & 10 & 8.1 & -8.43 & 157.06 \\
\hline 11 & 2007 & 8 & 15 & 23 & 40 & 39 & 8 & -13.38 & -76.61 \\
\hline 12 & 2007 & 9 & 12 & 11 & 10 & 34 & 8.5 & -4.44 & 101.37 \\
\hline
\end{tabular}




\section{Results and discussion}

\section{(1) Solar activity and the number of earthquakes with $M \geq 5$ during solar cycle 23}

Carrying out some statistical analysis and drawing graphs, we show the relationship between solar activity data and the number of earthquakes with $\mathrm{M} \geq 5$ during the 1996-2008 period (Fig. 1). It is also evident that in 2000 sunspot number is maximal and the earthquake number is maximal, in 2002 the sunspot number is in maximum but the earthquake number is in minimum, and in 2007 the earthquake number is in maximum when the sunspot number is in minimum.

Fig. 2 illustrates the relation between GEOS proton fluence $>100 \mathrm{MEV}$ and earthquake number with $M \geq 5$. We see that in 1997, 2000, 2003 the earthquake number and the GEOS proton fluence $>100 \mathrm{MEV}$ are in maximum and in 2007 the GEOS proton fluence $>100 \mathrm{MEV}$ is in minimum and the earthquake number is in maximum.

On Fig. 3 is illustrated the relation between the mean annual solar flux and earthquake number with $M \geq 5$. It shows that in 2000 the earthquakes number and the mean annual solar flux were in maximum, but in 2007 the mean annual solar flux was in minimum and the earthquake number is in maximum.

On Fig. 4 is illustrated the relation between both observed and corrected sunspot area and the earthquake number with $M \geq 5$. It shows that in 2005 the earthquakes number is in minimum when the sunspot area is in maximum and in 2007 the sunspot area and the earthquake number is in maximum.

From Fig. 1-4 we see that for earthquakes $M \geq 5$ near the maximum of the cycle 23 there is a direct relation between sunspot number, mean annual $10.7 \mathrm{~cm}$ solar radio flux, mean annual GEOS proton fluence and earthquake number.

Also, at the maximum of the cycle there is an inverse relation between the sunspot number and earthquake number, and a direct relation between GEOS proton fluence and earthquake number. Finally, at the descending phase of the cycle there is an inverse relation between sunspot number, mean annual solar flux, GEOS proton 
fluence and earthquake number and a direct relation between sunspots area and earthquake number.

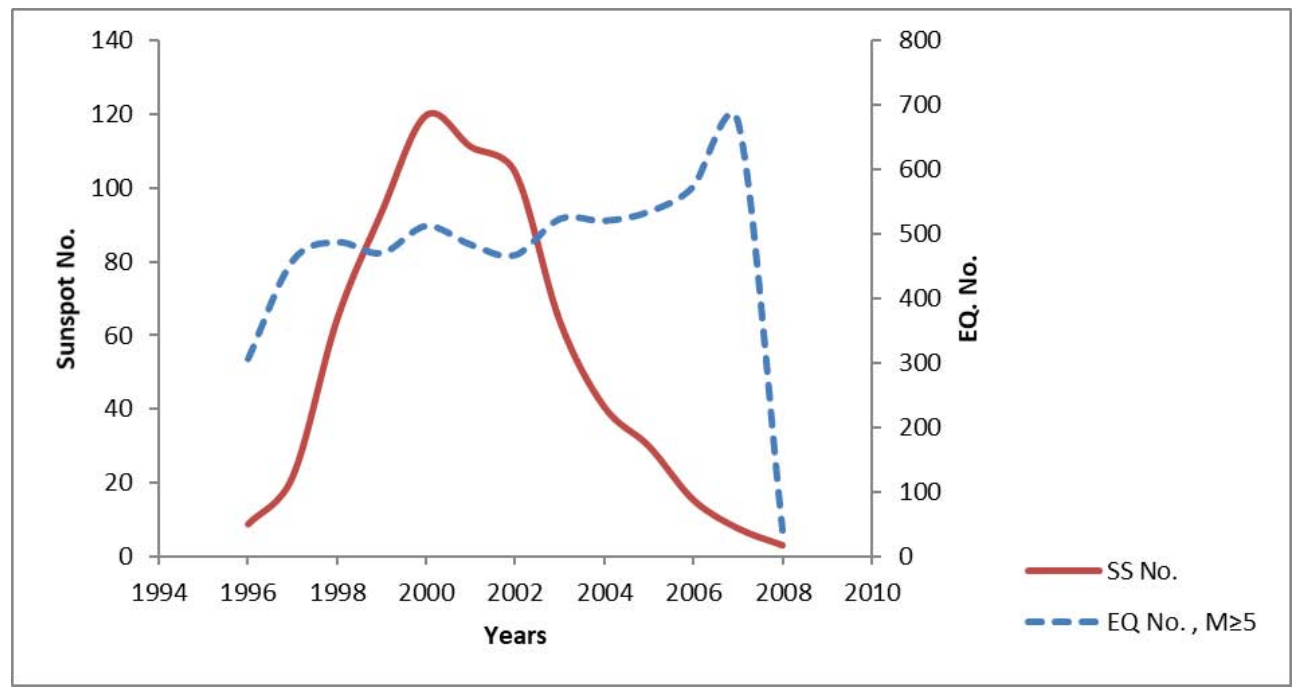

Fig. 1. Relation between sunspot number and the number of earthquakes with magnitude $M \geq 5$ during the solar cycle 23

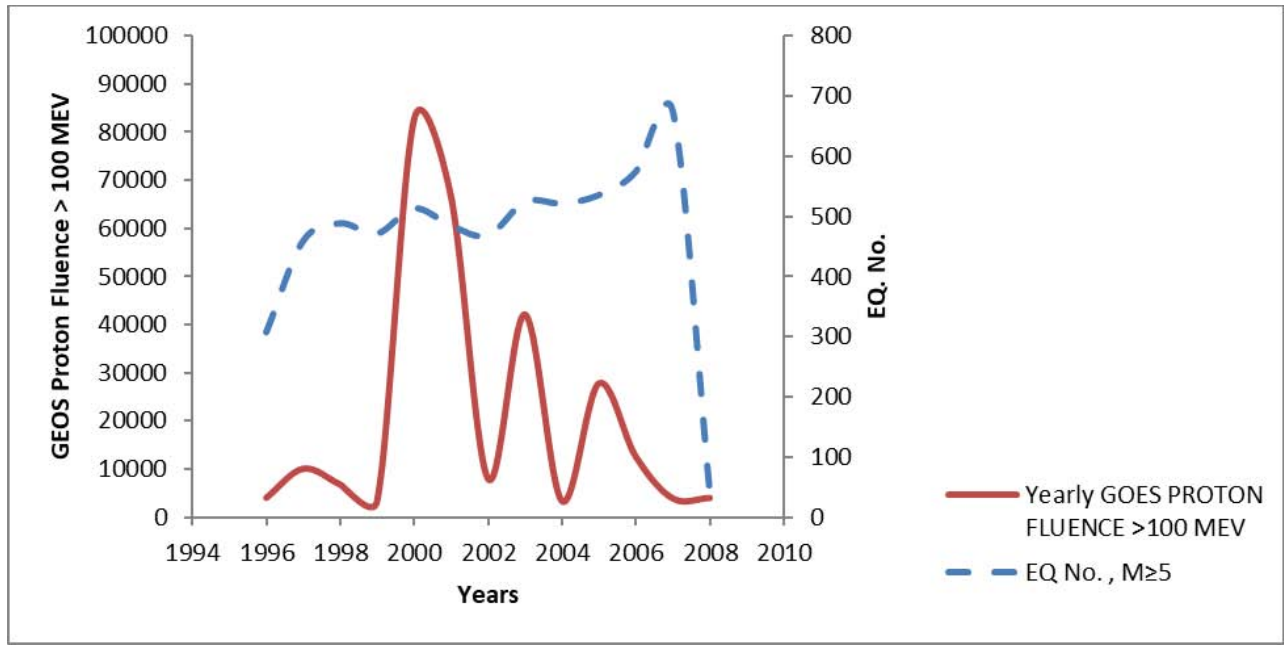

Fig. 2. Relation between GEOS proton fluence > $100 \mathrm{MEV}$ and the number of earthquakes with magnitude $M \geq 5$ during the solar cycle 23 


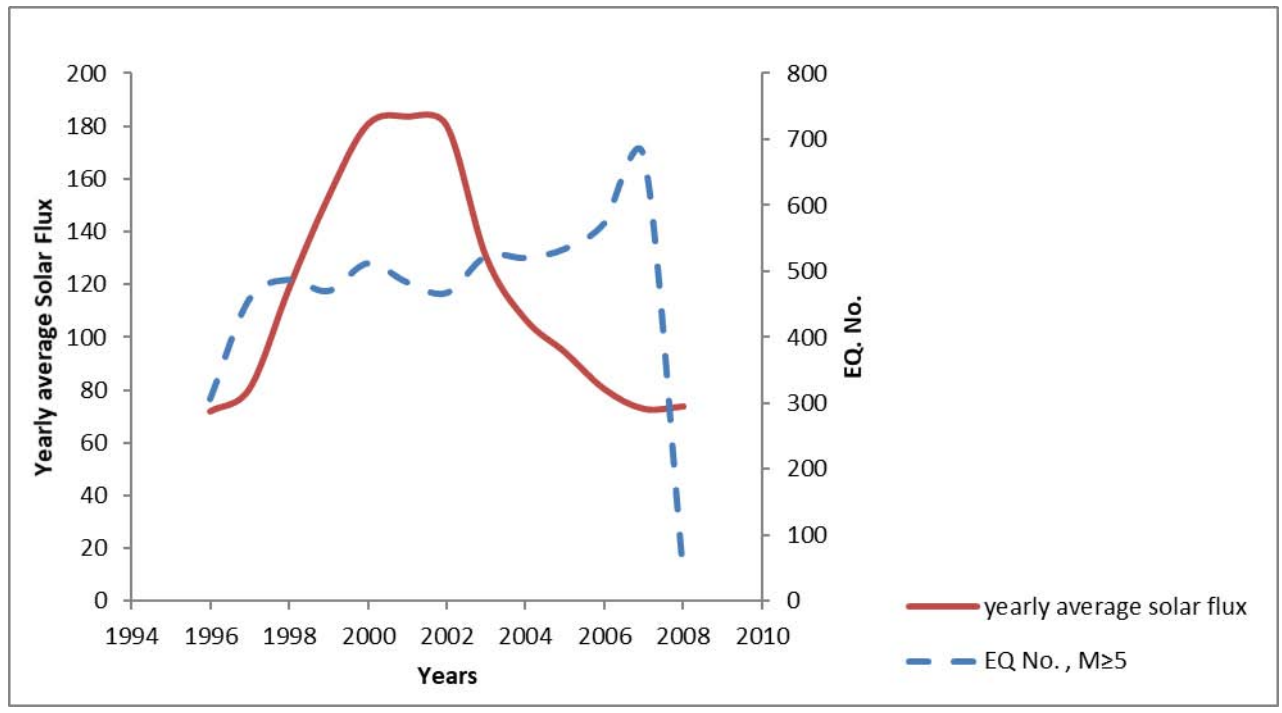

Fig. 3. Relation between mean annual solar flux and the number of earthquakes with magnitude $M \geq 5$ during the solar cycle 23 .

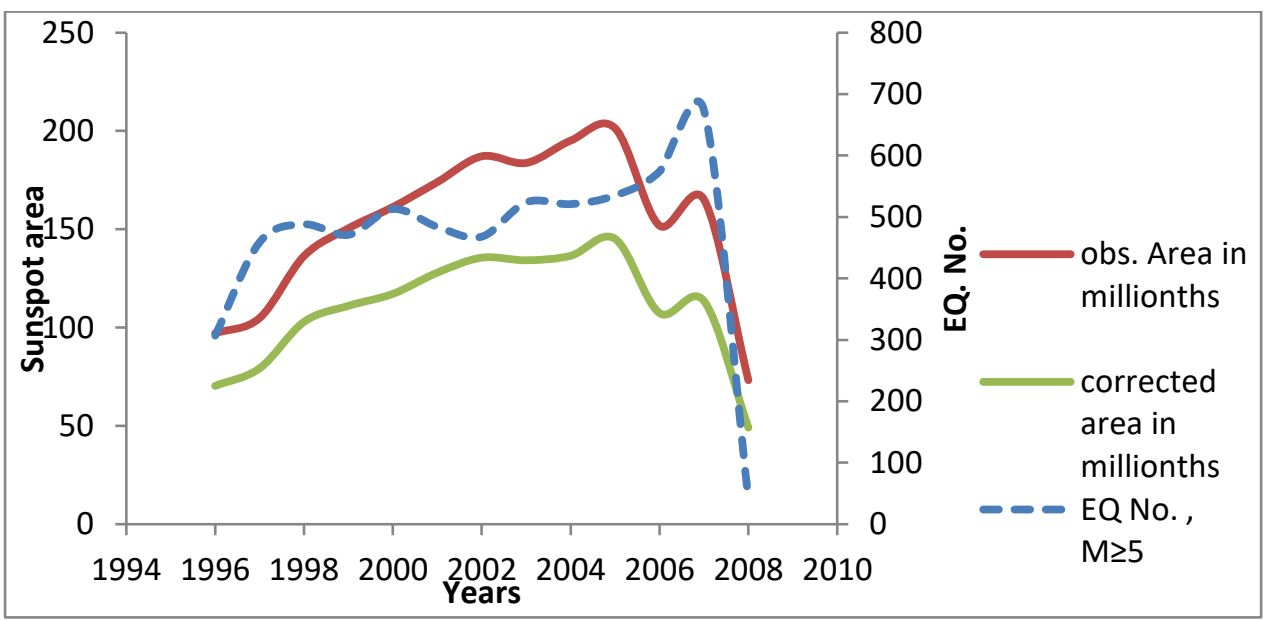

Fig. 4. Relation between both observed and corrected sunspot area and the number of earthquakes with $M \geq 5$ during solar cycle 23 


\section{(2) Solar activity and the number of earthquakes with $M \geq 8$ during solar cycle 23}

Carrying out some statistical analysis and drawing graphs, we have shown the relationship between the solar activity data and earthquake number with $\mathrm{M} \geq 8$ during the 1996-2008 period in Fig. 5. We see that in 2000 the sunspot number and the earthquake number are in maximum and in 2004 and 2007 the sunspot number is in minimum but the earthquake number is in maximum. Fig. 6 illustrates the relation between GEOS proton fluence $>100 \mathrm{MEV}$ and earthquake number with $\mathrm{M}$ $\geq 8$ and show that in 2001 the earthquake number and the GEOS proton fluence $>$ $100 \mathrm{MEV}$ are in maximum; in 1998, 2002 the GEOS proton fluence $>100 \mathrm{MEV}$ and earthquake number are in minimum and in 2004 and 2007 the earthquake number is in maximum when the GEOS proton fluence $>100 \mathrm{MEV}$ is in minimum. Fig. 7 illustrates the relation between mean annual solar flux and earthquake number with $M \geq 8$ and show that in 2001 the earthquake number and the mean annual solar flux are in maximum, in 2002 mean annual solar flux is in maximum and earthquake number is in minimum, and in 2007 the earthquake number is in maximum and the mean annual solar flux is in minimum. Fig. 8 illustrates the relation between both observed and corrected sunspot area and earthquake number with $\mathrm{M} \geq 8$ and show that in 2004 the earthquake number is in maximum when the sunspot area is in minimum and in 2007 the sunspot area and earthquake number are in maximum.

From Fig. 5-8 we obtain that for earthquakes with $M \geq 8$, there is a direct relation between the sunspot number, mean annual solar flux, GEOS proton fluence and earthquake number and an inverse relation during the descending phase of the cycle. Also, there is an inverse relation between the sunspot area in units of millionths of the sun's visible hemisphere and the earthquake number near the maximum of the solar cycle, and a direct relation during the descending phase of the solar cycle. 


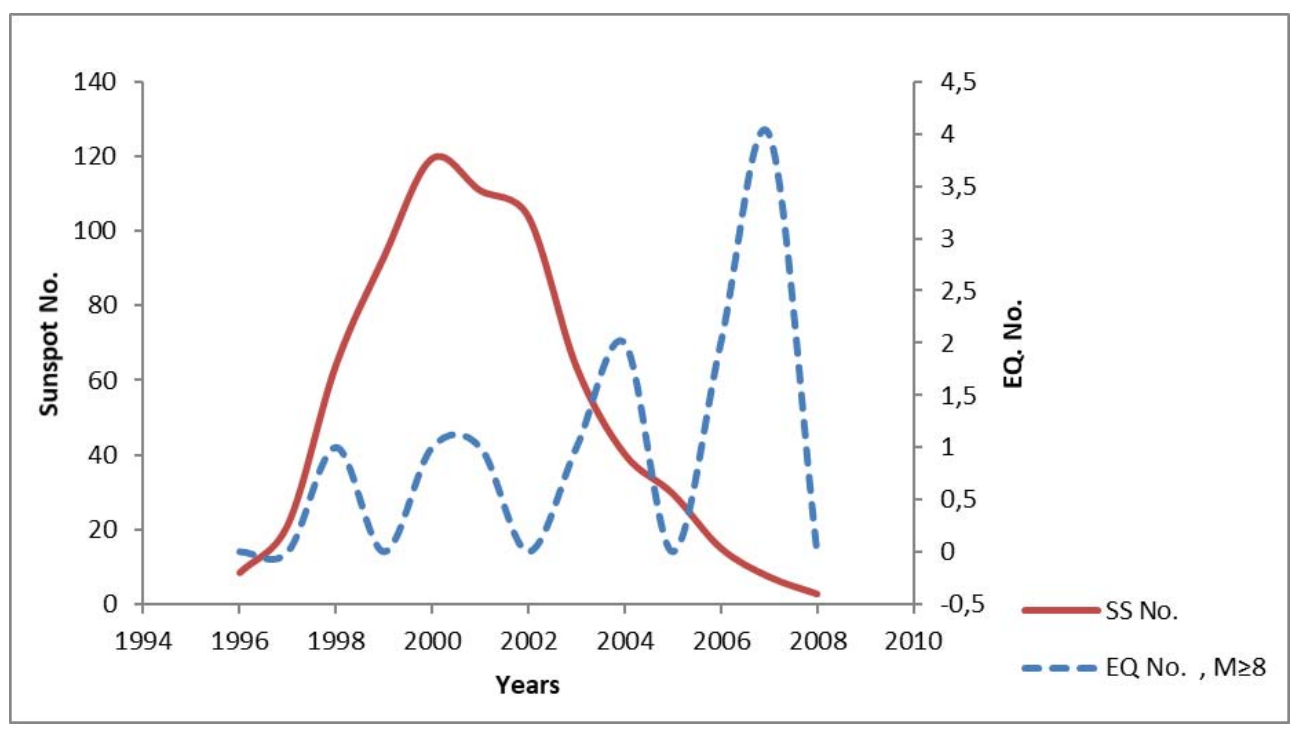

Fig. 5. Relation between the sunspot number and the number of earthquakes with $M \geq 8$ during solar cycle 23

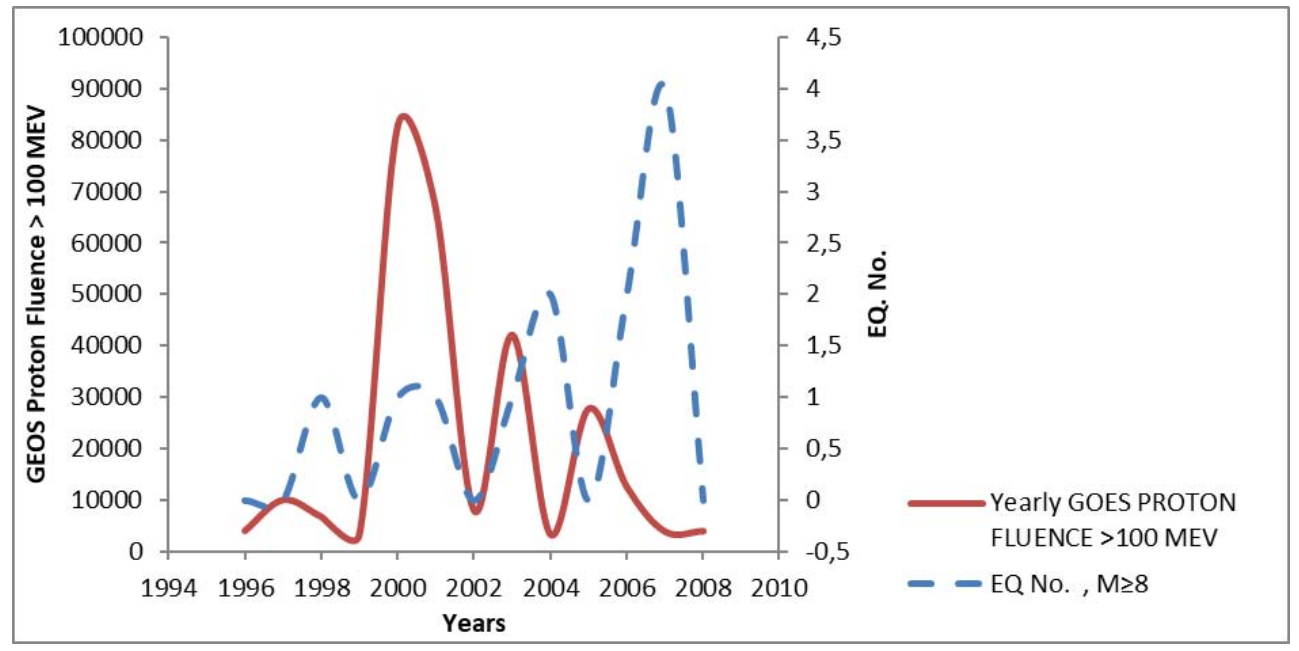

Fig. 6. Relation between the GEOS proton fluence > $100 \mathrm{MEV}$ and the number of earthquakes with $M \geq 8$ during solar cycle 23 


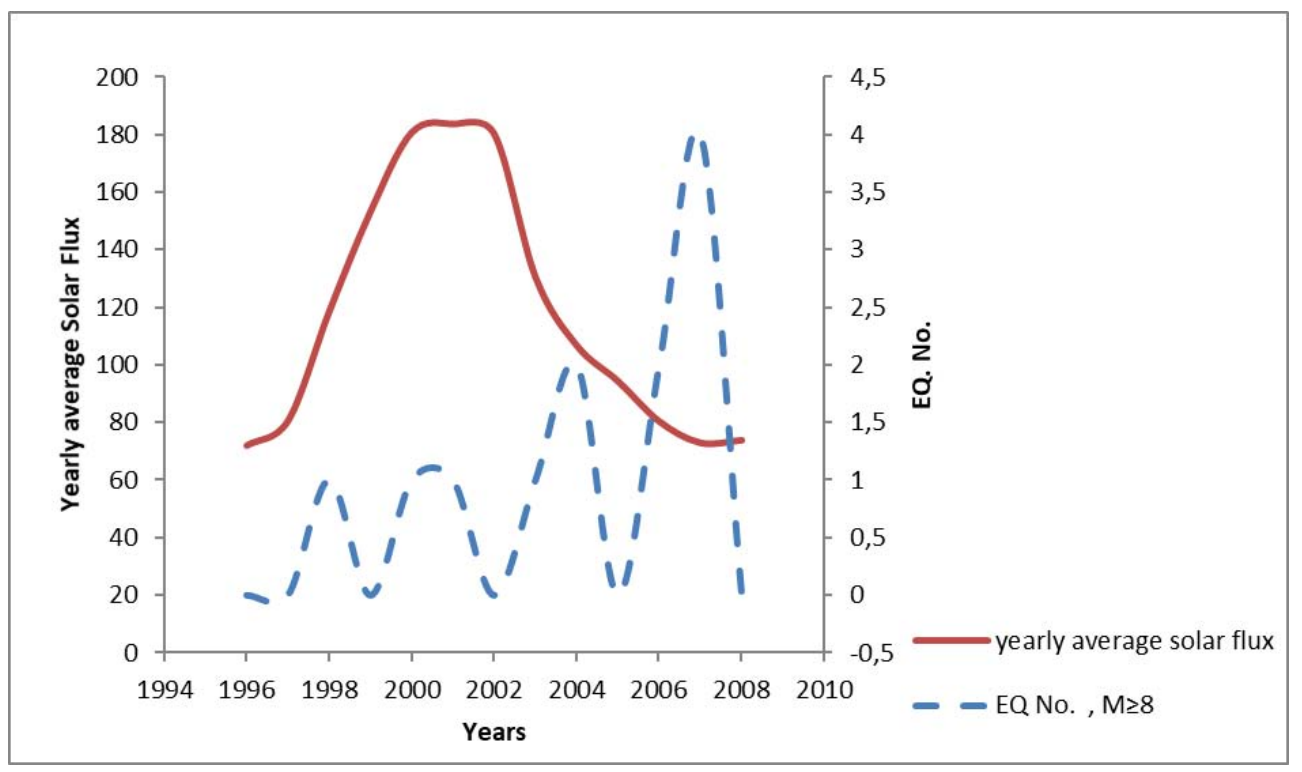

Fig. 7. Relation between the mean annual solar flux and the number of earthquakes with $M \geq 8$ during solar cycle 23

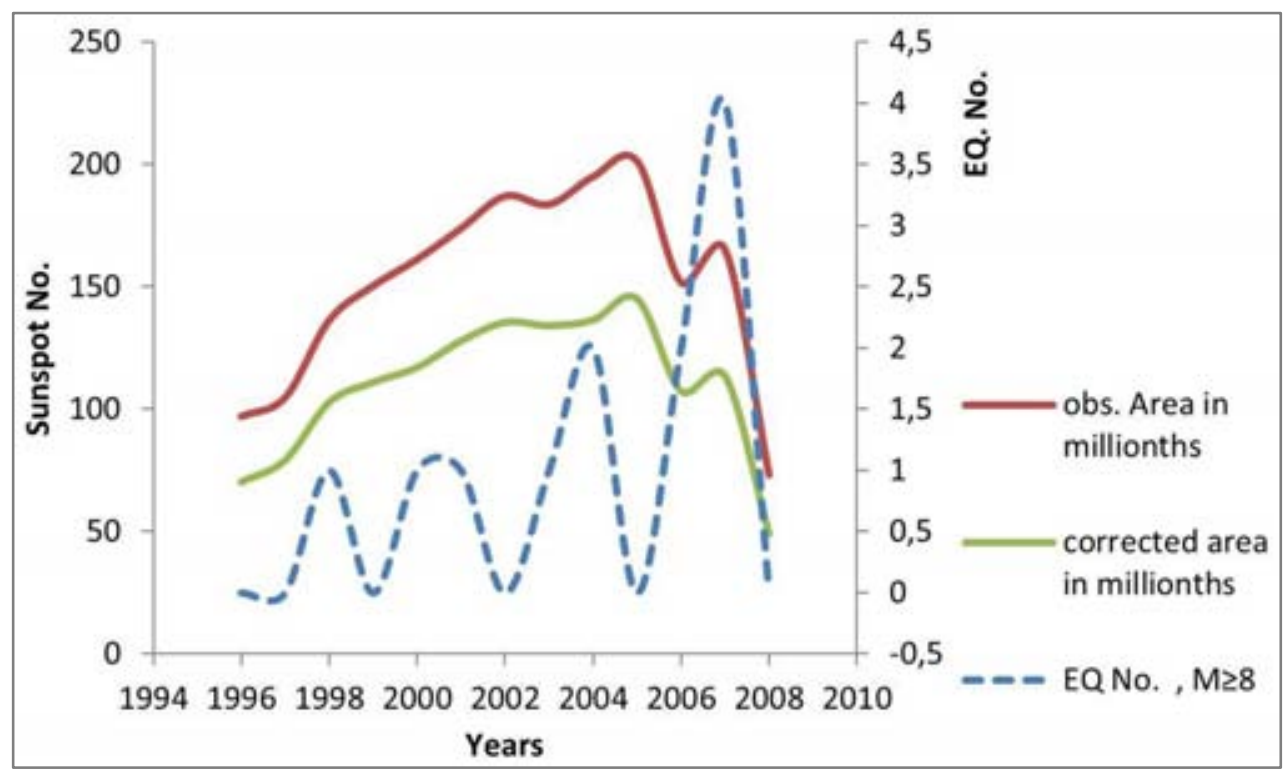

Fig. 8. Relation between both observed and corrected sunspot area and the number of earthquakes with $M \geq 8$ during solar cycle 23 


\section{Conclusion}

Youssef, 2003 [14] show that solar cycle 23 is a weak solar cycle of 11.7 years duration and has two peaks in 2000 and 2002. In the case of earthquakes of magnitude $\geq 5$, the number of earthquakes shows a peak at the minimum between cycles 23 and 24 as shown in Fig. 1.

There is a coincidence between the first activity peak of our studied cycle 23 in the year 2000 and the number of earthquakes. In the case of earthquakes of magnitude $\geq 8$, the cycle 23 has three peaks of maximum, descending branch and post the weak cycle (Fig. 5).

The proton fluence occurring at the $1^{\text {st }}$ maximum of this cycle is coincident with the $2^{\text {nd }}$ earthquake peak. It is clear that protons have great influence on triggering earthquake particularly for this cycle, which can be explained by the injection of solar protons into the Van Allen belts and hence in polar regions. Strong ionospheric electric currents can induce telluric currents in the earth's crust and deep into the magma perhaps at the epicenter of the earthquake.

So, the Earth Internal Effects $\left(\mathrm{EIE}_{\mathrm{s}}\right)$ are not the only reason for earthquakes. Solar activity also influences the processes going on the Earth. Our investigation show that the maximum of earthquakes frequently occur around the years of minimum in the solar activity cycle.

\section{References}

1. Zhang, Gui-Qing. Relationship between global seismicity and solar activities. ACTA SEISMOLOGICA SINICA, 1998, 11, 4, 495-500.

2. Sytinskiy, A. D. The influence of solar activity on earth seismicity. Akad. Nauk. SSSR, Dokl., 1973, 208(5), 1078-81.

3. Sytinskiy, A.D., On the relation between earthquakes and activity, Fizika Zemli, 1989, 2, $13-30$.

4. Simpson, J. F. Solar activity as a triggering mechanism for earthquakes. Earth and Planetary Science Letters, 1968, 3, 417-25.

5. Lursmanashvili, O.V. Possible influence of solar activity on the distribution of the earthquakes in the Caucasus. Akad. Nauk Gruz. SSR Soobshch., 1972, 65, 2, 309-12.

6. Odintsov, S., K. Boyarchuk, K. Georgieva, B. Kirov, and D. Atanasov, Long-period trends in global seismic and geomagnetic activity and their relation to solar activity. Physics and Chemistry of the Earth, Parts A/B/C, 2006, 31, 1-3, 88-93.

7. Dorman, L. I. Cosmic rays in the Earth's atmosphere and underground, Vol. 303: Kluwer Academic Pub., 2004.

8. Gerontidou, M., Vassilaki, A., Mavromichalaki, H., and Kurt, V. Frequency distributions of solar proton events. Journal of Atmospheric and Solar-Terrestrial Physics, 2002, 64, 5-6, 489-96.

9. Courtillot, V., Y. Gallet, J. L. Le Mouël, F. Fluteau, and A. Genevey, Are there connections between the Earth's magnetic field and climate?, Earth Planet. Sci. Lett., 2007, 253, $3,328-39$. 
10. Khain, V. E. and E. N. Khalilov, About possible Influence of solar activity upon seismic and volcanic activities: Long-Term forecast. Science without Borders, Transactions of the International Academy of Science H and E, 2007, 1.3, SWB, Innsbruck, ISBN 978-9952-451-01-6 ISSN 2070-0334.

11. Tavares, M. and A. Azevedo, Influences of solar cycles on earthquakes. Natural Science, 2011, 3, 6, 436-43.

12. Nikouravan, B., P. Saied, and M. Somayeh. The effect of solar cycle's activities on earthquake: a conceptual idea for forecasting. Disaster Advances, 2013, 6, 4.

13. Kane, R. P. Some Implications Using the Group Sunspot Number Reconstruction. Solar Physics, 2002, 205, 2, 383-401.

14. Yousef, S. Cycle 23, the first of weak solar cycles series and the serious implications on some Sun-Earth connections, ESA Publications Division, 2003, ISBN 92-9092-845-X, 177-180.

\title{
ИЗСЛЕДВАНЕ НА ВРЪЗКАТА МЕЖДУ СЛЬНЧЕВАТА АКТИВНОСТ И СЕИЗМИЧНОСТТА НА ЗЕМЯТА ПО ВРЕМЕ НА СЛАБИЯ 23-ТИ СЛЬНЧЕВ ЦИКЪЛ
}

\author{
М. Семеида, С. Ходайри, М. Ел Хадиди, Р. Хамед, \\ НІ. Юсеф, П. Стоева, А. Стоев
}

\section{Резюме}

В тази работа е изследвана връзката между броя на слънчевите петна, площта на слънчевите петна, слънчевото радиоизлъчване при дължина на вълната $10.7 \mathrm{~cm}$, слънчевите протонни събития и земетресенията с магнитуд $\mathrm{M} \geq 5$ и $\mathrm{M} \geq 8$, в интервала 1996-2008 г. от 23-ия слънчев цикъл. Намерена е пряка връзка между слънчевата активност и земната сеизмична активност при $\mathrm{M} \geq 5$ и $\mathrm{M} \geq 8$ близо до максимума на 23-ия слънчев цикъл и обратна връзка по време на низходящата фаза на сльнчевия цикъл. 